\title{
Using Modern Education Technique in Wasit University
}

\author{
https://doi.org/10.3991/ijim.v14i06.11539 \\ Abdul Hadi M. Alaidi \\ University of Wasit, Wasit, Iraq \\ Omar Hashim Yahya \\ Northern Technical University, Mosul, Iraq \\ Haider Th. Salim AlRikabi $\left.{ }^{(}\right)$ \\ University of Wasit, Wasit, Iraq \\ hdhiyabeuowasit.edu.iq
}

\begin{abstract}
This New learning educational methods, which depending on Learning Management System (LMS), have been used by universities in the top education universities in the world. However, most of the Iraqi universities use the traditional education methods in the classroom. The purpose of this study was to examine the benefit of using LMS in higher education. This study shows how to implement and use modern educational techniques in Engineering College of Wasit University. This paper shows that using modern education tools in the class lead to increase the productivity of student, save time with less effort for instructors with high accuracy of exam results. In addition, using LMS system allows students to obtain more information in a short time. Moreover, this system gives students an opportunity to interact with the instructor and among themselves. The findings show the benefits of integrating LMS in higher education and recommend other institutions to implement it.
\end{abstract}

Keywords-Higher Education; Learning Management System; Information and Communication Technology; Canvas

\section{$1 \quad$ Introduction}

It is very difficult for students to learn and understand engineering classes like mathematics without using classical education material as chalkboard or other educational material. It's an unthinkable mission for instructors to clarify without utilizing any instructive apparatuses. In the last decade, the educational methods have evolved dramatically. Firstly, instructors were using blackboard and chalk for leaning students then white boards. Finally, in the present time the instructors are using smart of whiteboards in their lecturers. According to[1], "Educational change depends on what teachers do and think - it is as simple and as complex as that." We believe that the instructor is the main key to the development of students' mental skills and success. Using of technological education within colleges by instructors has three main advantages. Firstly, the use of technological education saves time and gives an oppor- 
tunity for discussion between the student and the professor within the classroom. It is known that the time is money. California Department of Education ("Education Technology Planning," 2001) defines time as "Time is the greatest stumbling block" to provide significant and a high quality educational opportunities for teachers "to plan, reflect, design lessons together, and examine and make meaning of content and teaching standards." The use of educational technology in classroom reduces the stress of the professor and makes the teacher teach the students effectively and actively. Moreover, In-class technological education gives the student an incentive to continue learning. One of the biggest problems that confronted lecturers to teach huge number of students and it needs much of time while the technological education save time with high efficiency. For instance, some colleges have halls of lectures, and that will be tough to lecturers in additions to students[2]. California University, San Diego University, and Temple University solved this problem by using Room Control System (Goral, 2008).

Educators utilize innovation education in the classroom to enhance execution and utilize time viably. As of late, modern education technology has been created and utilized present day advancements to enable educators to decrease time utilization in instructing. According to[3] instructors can save lessen time essentially by creating a new technique to enhance the students for overcoming the difficulties that may face in composing or perusing. In fact, one of the best techniques way, according to[4], is utilizing media in the classroom. Utilizing sight and sound in class can support the achievement of success from $10 \%$ to $20 \%$ over customary adapting way and $33 \%$ sparing time on the undertaking[5]. For instance[6], announced that "Owing to the lack of time," he utilized the Interactive Whiteboards as an apparatus to show understudies and answer their inquiries concerning "heat and the process of floating." Dodd's and Fletcher[7] detailed that utilizing intuitive advances can decrease time by approximately $33 \%$. Also [8], said that sparing time is the undeniable outcome when we contrasting ordinary guideline and innovation direction. Table 1 clarifies the sparing time that[8] announced:

Table 1. Percent time saving for technology-based instruction

\begin{tabular}{|l|c|c|}
\hline \multicolumn{1}{|c|}{ Study (reference) } & Number of studies reviewed & Average Time saved (\%) \\
\hline Orlansky and string (1977) (Military training) & 13 & 54 \\
\hline Fletcher (1991) (higher Education) & 8 & 31 \\
\hline Kulik (1994) (higher Education) & 17 & 34 \\
\hline Kulik (1994) (Adult Education) & 15 & 24 \\
\hline
\end{tabular}

This table is considered as significant proof to demonstrate that reliance on modern technology in the classroom can both save and utilize time successfully.

The second reason educators rely upon instructive innovation in the classroom is to lessen the workload utilizing less push to give a more noteworthy impact when they educate. All educators are human and when they work they feel weariness that decreases their execution.

Information and Communication Technologies (ICT) and Virtual Teaching Assistants (VTA) are modern educational tools that may assist lecturers to reduce the ef- 
forts and enhancement their achievements. However, this could not happen without changing the role of professors and instructors toward the use of ICT. So, to reach their full potential "staff and student should receive appropriate training and support" [16]. Bordbar[9] reported that (ICT) is one characteristic of using development technologies tools like computer in the classroom to decrease the workload on the lecturer. One of big problems that face lecturers is the grading of student's test especially huge class, which is one of Wasit University example that can do multiple-choice exam in the electrical engineering department. The lecturers do not take time the correct papers exam, and the student can get his grade automatically after finish his exam. The huge number of papers exam may due to mistake the question correction or in the summation grade of questions. The modern technology exams tools show the results without any mistake and without spending much time. Chou, Huang and Lin[10] reported that (VTA), which are using modern ways to enhance the student for learning, can decrease the lecturer workload. Lecturers take much time to correct paper quizzes, exams, grade exams, or even the explanation in the classroom.

Modern educational technologies tools can decrease a lot of management paperwork and save workload of lecturer.one of the best ways, for instance, by utilization smart whiteboards. According to[11], smart Whiteboards can decrease the time of lecture preparation because it gives the instructor more option like searching on the internet. Moreover, using smart Whiteboards (IWB) can decrease instructor effort and the student remain interactive[12]. Morgan[11] prove the practice of Forrest, who responsible on mathematical class by using IWB, he shows that the using of smart board is a simple way for learning students because they will have more than one option for learning by using pin and manipulate text. Arias[13] did study and established that fifty percent of lecturers use modern technology tools "as a medium for curriculum" (p.11); in addition, they show 4 out of 6 lecturers consider the modern technology way assist them to qualify their load.

Another part of educational technologies is managing eLearning courses through learning management system "LMS", which this paper covers. The major concern in this paper is to support traditional educational method through LMS, which is not only to save time and money but also to deliver effective instruction that enhances interactive learning environment between students and faculties. However, creating effective courses and interactive learning environment through LMS would be great challenges that instructors should be aware of [14]. Can faculties face these challenges and increase students' performance and create interactive learning environment? Are designing Engineering courses through LMS would be applicable in all courses? This study answers these questions by presenting instructive case of how to implement and use modern educational techniques in Engineering College of Wasit University.

\section{The Need of LMS in Higher Education}

The emerging of LMS was at Illinois University in1960 [19]; it has gradually developed by the scholars to be integrated into academic organizations. Regards of the 
limitation of time and distance LMS is designed to face these obstacles by delivering asynchronous or synchronous eLearning and online classes and to support traditional teaching methods [18]. Nowadays LMS is a supportive tool for boosting learning process. The purpose of LMS is for enhancing communication among students and between instructors and students, share materials and communicate online. Delivering courses to a large number of dispersed students globally in a limited time would be demanding task through traditional teaching [14]. LMS which is web-based technology could meet these demands and delivering eLearning courses, virtual classes or online classes and supporting traditional teaching [24]. LMS, virtual learning environment or course management system are used interchangeably in e-learning environment to support student-centered learning, make learning content easily accessible and supportive with a variety of learning materials [23].

Recently, LMS has used among corporate and government organizations to academic universities and K-12. It helped to administrate, document, track, report and evaluate the whole learning process effectively [16]. Unquestionably, LMS has widely and commonly used among higher education in UK, Canada, USA and Australia and recently in developing country such as Iraq, Saudi Arabia and Jordan. For example, The National Centre for E-learning and Distance Learning (NCEL) in Saudi Arabia designed its own LMS called JUSUR which designed with "17 interactive tools" and they collaborate with Meteor Group of Companies in Malaysia [26].

With LMS professor or instructors can administrate, track and evaluate the whole learning process and see the progress of their students digitally. Students can do their test or deliver their assignments, view their grades, evaluate their progress and involved in group discussion through LMS which increase the theory of studentcentered [24]. Stakeholders in any learning community had studied all the possibilities to improve teaching strategies through pedagogical concept and to achieve effective learning outcomes, but they have faced challenges of accessibility and flexibility of teaching through e-Learning environment [27]. LMS had faced those challenges in addition to meeting learners' needs with various characteristics and meeting diverse learning style [27].

\section{$3 \quad$ What Can an LMS do in Higher Education?}

LMS is a better future of learning for higher education. LMS gives instructors opportunities to create tailored learning experience that fit every student's needs and give the ability to manage multiple classes worldwide [23]. Its system of creating interactive website and modules, built-in rubrics, assessment, grading, reporting, trucking students' progress, participation and attendance, and communication system make it the better supporting tool for creating desirable interactive learning environment[28]. LMS helps in planning, implementing and delivering instructions in multiple learning contexts and extend beyond traditional campus because it is organized around the learners' needs. LMS gives opportunity to apply different learning models such as blended learning - synchronous and asynchronous, storytelling, gamification, rapid learning etc [29]. Obviously, the variety of learning models could meet diverse 
learners' needs and they can be self-directed and self-paced and meet their individual progress. They can also get immediate feedback, be involved in valuable discussion groups. Undoubtedly, with traditional teaching method which is based on teachercentered, students would not be able to achieve the desirable learning outcome [22]. LMS replaced the traditional design of teaching to learner-centered design and replaced traditional methods of getting information, submitting assignment or doing a test. For example, students can view several supported links and resources for their interested subject that support their educational attainment [20].

Stakeholders and professors can administrate, document, organize and manage modules and the status of the course, distribute materials, upload online resources or share MOOCs that support their main course, post immediate feedback with grades, track students' progress and assess and view statistical data about the learning outcome and LMS quality [19]. When a new course is introduced it could be no access for students to view a course syllabus before signing up for a course, but with LMS student can view the introduction of the course and the instructor teaching method and the announcement in its calendar [19][20]. Without LMS it would be most difficult to support the theory of learner-centered approach and deliver instructions in different learning style and create the interactive environment between students and professors in an effective way and with cost-effectiveness. So, it is obvious that LMS has been suggested for higher education by scholars and stakeholders to integrate it into their classes to achieve the desirable learning outcome.

\section{$4 \quad$ Features of LMS in Higher Education}

The functional LMS was built on pedagogical theory and learning theories such as "behaviorism, cognitive theory, and constructivism" to achieve the desired learning outcomes and meet organizations' goal [15]. As [14], [15], [29] and [16] detailed some features to state the fit LMS that meet individual needs. LMS should be adapting to learners' and instructors' needs such as the ability to choose from the variety of the learning models. Instructors' should be able to create interactive modules, delete or add new course independently. Most LMS has been integrated with registration portal to give access to their students to register for a class.

User friendly is another feature makes stakeholders interested in LMS. The friendly interface to navigate and accessing information and activities easily and quickly was faster their work to be done. LMS is an organized system so instructors can easily create organized modules with relevant contents and online readily available materials, create online quizzes and syllabus and upload varieties of files and online resources.

Easy access: That is accessible with the whole functionality from any mobile device - laptop, smartphone or tablet anytime. This has helped students to complete their assignment and upload it from anywhere, collaborate together in a discussion group, and get feedback from their peers and teachers [14].

Interactive learning and communication: Creating interactive modules in the form of PDFs, video clips, audio, or online resource and encouraging students to pre- 
pare for the class prior to class time can support traditional class. That is instructors made substantial discussion in the class time and decrease the workload and save time. Instructors need to engaging students in discussion forums which facilitate communication between them [[16] about class. When students post questions online and get responses and critical ongoing feedback from their peers and instructor, they learn from each other and promote learning process [29]. Also, motivation is part of interactive learning experience. Students need to feel motivated i.e. their names are on the leaderboard and to enhance motivation instructors can utilize the feature of gamification - another learning strategy within LMS [25]. Gamification helps students to remember what they have learned through "game mechanics" which is tailored to meet course learning objectives [30].

Trucking Data for learners' progress: Collecting data to analyze learners' performance and close their gaps can be in many forms in LMS. The build-in rubrics help instructors to grade students' assignments effectively and measure their progress. Students can do their quizzes online and view their score immediately. Instructors' feedback, grade statistics and other learning activities are help instructors to collect data about students' proficiency, truck their progress and close any gap in teaching [28]. Trucking data is not just help instructors to close learns' gap, but also help students to focus on what they need to learn [28].

\section{$5 \quad$ Design and Implementation of LMS}

The proposed method for implementing the system is to use three servers with main router and four switches. The servers are one of the most important part of the system because they provide the services for all users, which will be responsible for storing all data and information, including database and archiving, in a manner that ensures that this information is not lost. In addition, these servers provide the transfer of information between large numbers of users simultaneously with high efficiently. Therefore, our College provides three high-performance servers. The first one is HP ProLiant DL380p Gen8 E5-2620 with 24 processor and random memory capacity of 48 Gigabyte. The others are HP ProLiant DL380 G7 type with specification of two processors (Intel Xeon E5640), random memory capacity of 16 Gigabyte, and large storage capacity ( 2 terabytes) with RAID 5 data storage for four parallel hard drives, to ensure that data will not lost even if one of these discs' malefaction. The fiber optics is used for connection between the main router and branches of switches. The switches are distributed for four engineering departments (Electrical, Civil, Mechanical, and Architecture). There are two types of Wi-Fi devices in each department. The first type which has more capability to serve more crowded places like student classes, Laboratories, Workshops, and student club while the other Wi-Fi types serve less crowded places like faculty, management, and control rooms. Figure 1 shows the Architecture of engineering college network and figure 2,3 show the installation of Wi-Fi and Fiber optic. 


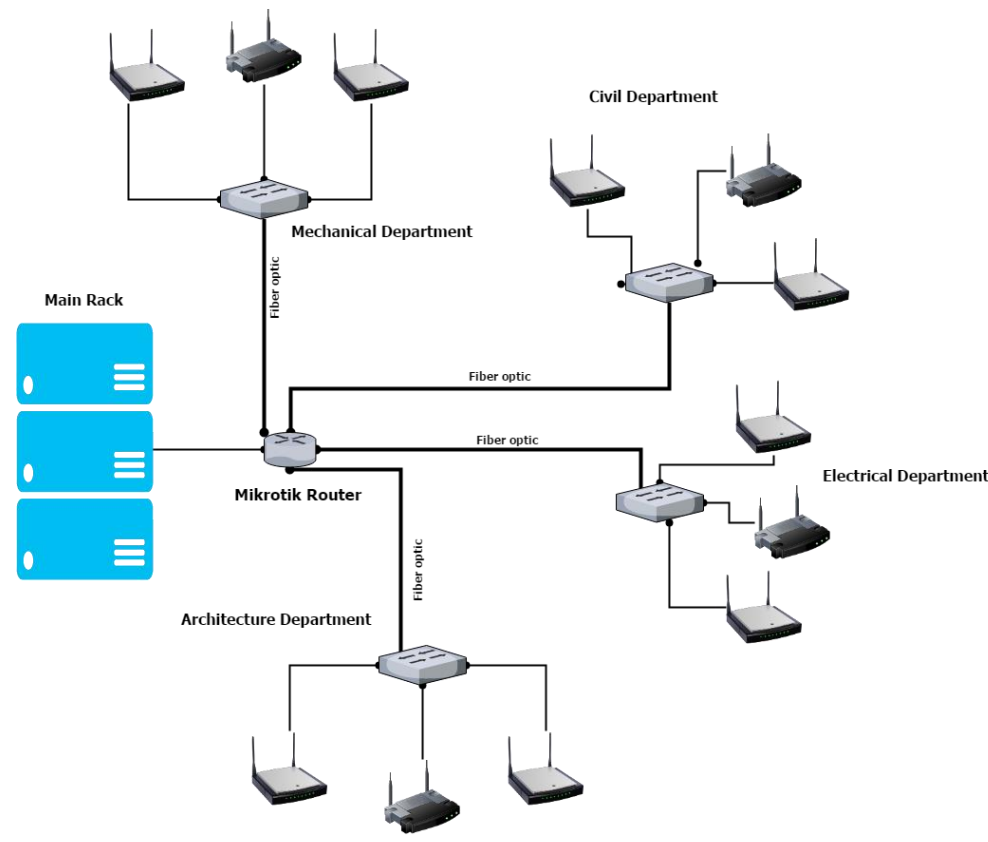

Fig. 1. Architecture of engineering college network.

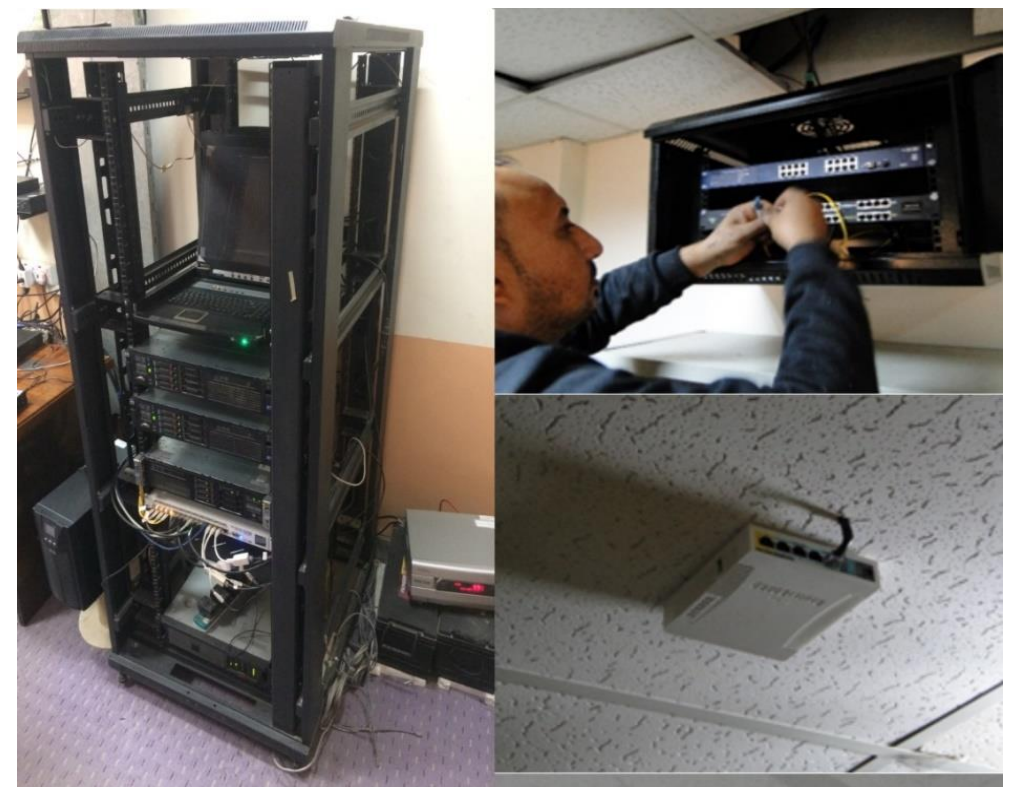

Fig. 2. Fiber optic and Wi-Fi installation. 


\section{Conducting Workshops}

The support team and instructional design team conducts general workshops on how to use LMS particularly Canvas platform. During the workshops, they discussed generally faculty's technological barriers of integrated educational technology into instructions and learners characteristics to implement LMS effectively. The team encouraged interaction, provided live examples and interactive activities. Also, the support team worked with different Engineering departments - civil, mechanical and electrical - to develop multimedia materials that beneficial for students' learning.

\section{$7 \quad$ Why Canvas}

\subsection{Features of canvas platform}

Finding LMS application that fit into any learning environment and meets all parties' needs - organization, learners, and faculty -would be very challenging [27] and [28]. Most functional LMS has easy access feature, helping students to access course material and assignment anytime. Because of accessibility, students are able to submit their assignments from any mobile device. The user-friendly interface makes it easier for both instructors and learners to easy engage with course materials and communicate with peers and instructors easily. With LMS instructors are able to manage enrollments, share documents, trucking data - assignment and test assessments and grading - share course materials, upload course syllabus and varieties of files. In addition of these features students also have the ability to be engaged in online environment and in discussion group and find additional educational resources. Other tools such as a quiz grading book, a dashboard page, and customizable notifications, quizzes tool for practicing or doing quiz are effective features that support learning process. Meeting those features depends on the organization's needs and goal [14] and some of e-Learning LMS software that has those features is Moodle, Canvas, Edmodo and Blackboard.

Canvas LMS is an open source learning management system developed by Instructure. It provides much functionality depending on web 2.0 technologies. Free version of Canvas distribution has many features: assignments, quizzes, curriculum and polls supported by specialized grading tool. Moreover, Canvas LMS offers file sharing where users have their own file repositories, wiki pages', discussions and messaging system. Announcements, scheduling and presentation tools are also supported by Canvas. A specialized tool is using to create user's portfolios and web pages. In another hand, Canvas offers many tools for system admin: accounts, group with different permissions membership where only enrolled use can access a course organization. Canvas gives the admin ability to customize course organization and navigation. System monitoring is another tool provide by canvas where automatized tasks such as message exchange can be monitored. Third-party tools can be added to extend canvas feature. So far, there are numerous external applications and plug-ins for Canvas. 
In order to keep up with what student doing and what expected from them Canvas offers an "Observer" role. Observer user can read documents and pages, check the calendar, assignments, announcements, and see quizzes. However, Observers cannot read quiz content, submit any quizzes or assignments, and send messages to students. In case of link an observer to a student the observer can see the student's grades and course interactions.

Because of all of those features of Canvas and more, many educators in USA has established their free online courses known as massive open online course "MOOC" for academic support and they also extended it to professional development.

\section{$8 \quad$ Result}

The modern education method which concerned in this study has been applied in Engineering college / Wasit University for master comprehensive exam for electrical engineering departments and compared the result with others departments which used traditional method for same exam and the result reported in table II.

Table 2. Saving time, number of monitors and objection for comprehensive exam

\begin{tabular}{|l|c|c|c|c|c|}
\hline Department & $\begin{array}{c}\text { Student } \\
\text { Number }\end{array}$ & $\begin{array}{c}\text { Exam } \\
\text { time }\end{array}$ & $\begin{array}{c}\text { No. of objection } \\
\text { on result }\end{array}$ & $\begin{array}{c}\text { No. monitors } \\
\text { exam }\end{array}$ & $\begin{array}{c}\text { Time of announce the } \\
\text { results }\end{array}$ \\
\hline Civil & 21 & $3 \mathrm{hr}$ & 2 & 4 & $24 \mathrm{Hr}$ \\
\hline Mechanical & 20 & $3 \mathrm{hr}$ & 1 & 4 & $24 \mathrm{Hr}$ \\
\hline Electrical & 16 & $3 \mathrm{hr}$ & 0 & 2 & $0 \mathrm{hr}$ \\
\hline
\end{tabular}

Depending on the results which shown in the above table, we conclude that there is no needing for time to announce the result of the comprehensive exam of electrical engineering results because the results are shown directly to the students. Moreover, the number of monitors in examination hall was reducing by $50 \%$. Furthermore, there is no objection from any student on the grade.

The result of the survey has shown that most of the instructors who participated in the integration of LMS Canvas have shown initiative to build web-based course materials. The majority of them agreed Canvas was easy to use and easy to create the complete course with multimedia materials which made course enrich. They acknowledged that their teaching strategies had changed and supported their face to face "F/F" classes. The in-service instructors who worked with their peers indicated that some instructors continue in creating engaging activities that encourage interaction among students and their peers and instructors. Indeed, stakeholders will work together to expand the integration of LMS into higher education in Wasit university.

\section{Conclusion}

The studied in this paper focused on special program (Canvas) to help instructors for teaching. Using this method of modern technology can decrease a workload, notwithstanding sparing time, and save money with high efficiency. The instructors rely 
upon instructive innovation in the classroom is to give understudies inspiration to proceed with the learning. The implementation of modern education tools in our college gave excellent results by applying in comprehensive exam of master students. In addition, this study proves that using modern method of education in classroom avoid the mistakes that instructor may face by correction of exam paper or transfer grades from students' paper to master sheet. Even though this study examined the benefit of integrating LMS into higher education and encouraged similar academic institutions to integrate e-learning to support $\mathrm{F} / \mathrm{F}$ classes to reach the desirable learning outcomes, they did not cover the barriers of using LMS in higher education. It would be very challenging to create interactive class and engaging activities that make students more involved in and build interactive ongoing efficient communication[27]. So this study could be extend to examine the key factors that influence the diffusion and infusion of LMS to be adopted by higher education and making successful integration.

\section{References}

[1] M. Fullan, "with Stiegelbauer, S.(1991)," The new meaning of educational change, vol. 2, 1991.

[2] M. Brandsteidl, K. Wieland, and C. Huemer, "Novel Communication Channels in Software Modeling Education," in MoDELS Workshops, 2010, vol. 6627, pp. 40-54: Springer. https://doi.org/10.1007/978-3-642-21210-9_5

[3] C. Farivar, "Library shuffles its collection," ed: Wired, 2005.

[4] E. C. Schmid, "Potential pedagogical benefits and drawbacks of multimedia use in the English language classroom equipped with interactive whiteboard technology," Computers \& Education, vol. 51, no. 4, pp. 1553-1568, 2008. https://doi.org/10.1016 /j.compedu.2008.02.005

[5] A. M. Eskicioglu and D. Kopec, "The ideal multimedia-enabled classroom: Perspectives from psychology, education, and information science," Journal of Educational Multimedia and Hypermedia, vol. 12, no. 2, pp. 199-221, 2003.

[6] S.-J. Jang, "Integrating the interactive whiteboard and peer coaching to develop the TPACK of secondary science teachers," Computers \& Education, vol. 55, no. 4, pp. 17441751, 2010. https://doi.org/10.1016/j.compedu.2010.07.020

[7] P. Dodds and J. Fletcher, "Opportunities for new" smart" learning environments enabled by next generation Web capabilities," INSTITUTE FOR DEFENSE ANALYSES ALEXANDRIA VA2004.

[8] J. Fletcher, "Does this stuff work? A review of technology used to teach," TechKnowlogia, Jan-Mar, 2003.

[9] A. J. J. o. I. T. E. R. Tella, "Reliability and factor analysis of a blackboard course management system success: A scale development and validation in an educational context," vol. 10, no. 1, pp. 55-80, 2011. https://doi.org/10.28945/1368

[10] B. K. Mohammed, R. F. Chisab, and H. J. I. J. o. I. M. T. Alrikabi, "Efficient RTS and CTS Mechanism Which Save Time and System Resources," vol. 14, no. 04, pp. 204-211, 2020. https://doi.org/10.3991/ijim.v14i04.13243

[11] F. Bordbar, "English teachers' attitudes toward computer-assisted language learning," International Journal of Language Studies, vol. 4, no. 3, 2010. 
[12] C.-Y. Chou, B.-H. Huang, and C.-J. Lin, "Complementary machine intelligence and human intelligence in virtual teaching assistant for tutoring program tracing," Computers \& Education, vol. 57, no. 4, pp. 2303-2312, 2011. https://doi.org/10.1016/j.compedu.2011.06.005

[13] H. Morgan, "Teaching with the interactive whiteboard: An engaging way to provide instruction," Focus on Elementary, vol. 22, no. 3, pp. 3-7, 2010.

[14] N. Selwyn, Education and technology: Key issues and debates. Bloomsbury Publishing, 2016.

[15] O. H. Yahya, H. Alrikabi, I. A. J. I. J. o. O. Aljazaery, and B. Engineering, "Reducing the Data Rate in Internet of Things Applications by Using Wireless Sensor Network," vol. 16, no. 03, pp. 107-116, 2020. https://doi.org/10.3991/ijoe.v16i03.13021

[16] C. Arias, L. Baker, C. Degano, R. Mercado, N. Reynolds, and M. Smith, "EDUC 607 Professor Murillo March 18, 2009."

[17] D. Peraya et al., "Between what we say and what we think: Where is mediatization?" 2019.

[18] R. J. J. o. L. D. Epping, "Innovative use of Blackboard® to assess laboratory skills," vol. 3, no. 3, pp. 32-36, 2010.

[19] N. A. Alias and A. M. J. M. o. j. o. i. t. Zainuddin, "Innovation for better teaching and learning: Adopting the learning management system," vol. 2, no. 2, pp. 27-40, 2005.

[20] D. A. Falvo and B. F. J. T. Johnson, "The use of learning management systems in the United States," vol. 51, no. 2, pp. 40-45, 2007.

[21] W. Watson and S. L. Watson, "An argument for clarity: What are learning management systems, what are they not, and what should they become," 2007.

[22] M. J. S. J. H. E. S. Asiri, "Factors influencing the use of learning management system in Saudi Arabian higher education: A theoretical framework," vol. 2, no. 2, pp. 125-137, 2012.

[23] M. K. Kim, S. M. Kim, O. Khera, J. J. T. I. Getman, and H. Education, "The experience of three flipped classrooms in an urban university: an exploration of design principles," vol. 22, pp. 37-50, 2014. https://doi.org/10.1016/j.iheduc.2014.04.003

[24] P. A. J. E. t. r. Ertmer and development, "Teacher pedagogical beliefs: The final frontier in our quest for technology integration?" vol. 53, no. 4, pp. 25-39, 2005. https://doi.org/10.10 $\underline{07 / b f 02504683}$

[25] D. S. Walker, J. R. Lindner, T. P. Murphrey, and K. J. Q. R. o. D. E. Dooley, "Learning management system usage," vol. 17, no. 2, pp. 41-50, 2016.

[26] M. Abdel-Basset, G. Manogaran, M. Mohamed, E. J. C. Rushdy, C. Practice, and Experience, "Internet of things in smart education environment: Supportive framework in the decision-making process," vol. 31, no. 10, p. e4515, 2019. https://doi.org/10.1002/cpe.4515

[27] A. Raman and M. Rathakrishnan, "Blended Learning in Higher Education 4.0: A Brief Review," in Redesigning Higher Education Initiatives for Industry 4.0: IGI Global, 2019, pp. 70-84. https://doi.org/10.4018/978-1-5225-7832-1.ch005

[28] R. W. Lancaster, A comparison of student-centered and teacher-centered learning approaches in one alternative learning classroom environment. Arkansas State University, 2017.

[29] H. T. S. ALRikabi, Alaidi, Abdul Hadi M,Abed, Faisal Theyab "Attendance System Design And Implementation Based On Radio Frequency Identification (RFID) And Arduino," Journal of Advanced Research in Dynamical Control Systems, vol. SI 10, no. 4, p. 6, 2018.

[30] N. A. Hussien, I. K. Ajlan, M. F. M. Firdhous, and H. T. S. J. I. J. o. I. M. T. Alrikabi, "Smart Shopping System with RFID Technology Based on Internet of Things," vol. 14, no. 04, pp. 17-29, 2020. https://doi.org/10.3991/ijim.v14i04.13511

[31] S. Ko and S. Rossen, Teaching online: A practical guide. Taylor \& Francis, 2017. 
[32] C. L. Chang, "Faculty perceptions and utilization of a learning management system in higher education," Ohio University, 2008.

[33] R. M. Palloff and K. Pratt, Building learning communities in cyberspace. San Francisco: Jossey-Bass, 1999.

[34] H. T. Alrikabi, A. H. M. Alaidi, A. S. Abdalrada, and F. T. J. I. J. o. E. T. i. L. Abed, "Analysis the Efficient Energy Prediction for 5G Wireless Communication Technologies," vol. 14, no. 08, pp. 23-37, 2019. https://doi.org/10.3991/ijet.v14i08.10485

[35] W. H.-Y. Huang and D. J. R. R. S. B. E. i. A. Soman, Rotman School of Management, University of Toronto, "Gamification of education," 2013.

[36] J. H. Stronge, Qualities of effective teachers. ASCD, 2018.

[37] T. H. J. J. o. E. T. Spotts and Society, "Discriminating factors in faculty use of instructional technology in higher education," vol. 2, no. 4, pp. 92-99, 1999.

[38] Y. Zhao, K. Pugh, S. Sheldon, and J. L. J. T. c. r. Byers, "Conditions for classroom technology innovations," vol. 104, no. 3, pp. 482-515, 2002.

\section{Authors}

Abdul Hadi M. Alaidi is presently one of the faculty college of Electrical Engineering Department, College of Engineering, Wasit University Wasit,Iraq. He received his B.Sc. degree in computer Science from Al Mustansiriya University in Baghdad, in 2007. His M.Sc. degree (2014) in Computer Science and Engineering from University of Bridgeport, CT, USA. He interested in research areas such as Remote-Control systems and the applications of IOT, signal processing, Digital Communications systems, Embedded systems. Contact: -+964 7724903292. The number of articles in national databases -.4 The number of articles in international databases -4. E-mail: - alaidi@uowasit.edu.iq

Omar Hashim Yahya is presently one of the faculty college of the computer technology engineering department in the technical College of Mosul, Northern technical University, Mosul, Iraq. Also he is the Director of the Career development Center in The Northern Technical University. He received his B.Sc. degree in computer technology Engineering in 2006 from the technical College of Mosul, Mosul, iraq. his M.Sc. degree (2014) in Computer Science and Engineering from University of Bridgeport, CT, USA. He interested in research areas such as Remote Control systems and the applications of IOT, signal processing, Digital Communications systems, Embedded systems. Northern Technical University, Mosul, Iraq. Contact: -+964 7722118786. The number of articles in national databases -1 . The number of articles in international databases - 3. E-mail: - omer_h_yahya@ntu.edu.iq.

Haider Th. Salim ALRikabi is presently one of the faculty College of Engineering, Electrical EngineeringDepartment, Wasit University in Al Kut, Wasit, Iraq. He received his B.Sc. degree in Electrical Engineering in 2006 from the Al Mustansiriya University in Baghdad, Iraq. His M.Sc. degree in Electrical Engineering focusing on Communications Systems from California state university/Fullerton, USA in 2014. His current research interestsinclude Communications systems with mobile generation, Control systems, intelligent technologies, smart cities, and Internet of Things (IoT). Al Kut city - Hay ALRabee, Wasit, Iraq. Contact: - +9647732212637. The 
Paper-Using Modern Education Technique in Wasit University

number of articles in national databases -8 . The number of articles in international databases - 10. E-mail: - hdhiyab@uowasit.edu.iq

Article submitted 2019-08-18. Resubmitted 2020-02-09. Final acceptance 2020-02-23. Final version published as submitted by the authors. 